\title{
Construction of Innovative Experimental Center in University against the backdrop of "Made in China 2025"
}

\author{
Yi Jiangang*, Chen Zhen, Ju Shiwei \\ School of Electromechanical and Architectural Engineering \\ Jianghan University \\ Wuhan, China \\ yjg_wh@yeah.net
}

\begin{abstract}
In order to meet the new requirements for scientific research on equipment manufacturing in universities against the backdrop of "Made in China 2025", this article presents the necessity and urgency of carrying out the construction of innovative experimental center. By integrating the laboratories of electromechanical system modeling, simulation, design, test and diagnosis, the direction and the development ideas for related laboratories construction are proposed, which have the reference to the establishment of the innovative experimental center in universities.
\end{abstract}

Keywords-Innovative Experimental Center; College education; Laboratory construction; advanced manufacturing

\section{INTRODUCTION}

In March 2015, Premier Li Keqiang made a grand plan of "Made in China 2025" when he made a report on the work of the government at the two sessions. "Made in China 2025", which is a major strategic plan for the overall improvement of the quality and level of Chinese manufacturing industry under the new international and domestic environment, is based on the general trend of international industry changes. The purpose of this strategy is to change the situation of Chinese manufacturing industry which is "big but not strong". It is supposed that, through 10 years of efforts, China is going to join in the ranks of advanced manufacturing countries. It is obvious that establishing strong equipment manufacturing industries is the fundamental guarantee for enhancing China's comprehensive national strength and achieving industrialization, for the development level of equipment manufacturing industry reflects the comprehensive supporting ability of a country in science and technology, process design, materials, processing and manufacturing, etc [1-2].

As the country starts to set up the layout of advanced highend equipment manufacturing industry and the related support policies have been introduced, in the next ten years, high-end equipment manufacturing industry will hug its gold growth period. The attractive industry prospects and the national policies of financial support have made the advanced high-end equipment manufacturing industry as the popular keywords in the 13th Five-Year Plan of China's local governments. In the form of development, China has now entered the ranks of equipment manufacturers. However, China cannot be regarded as a powerful country for equipment manufacturing because of the lack of core technologies [3-4]. Only carrying out relevant innovative experimental center construction and strengthening related basic science and technology research in university can we make China quickly enter into the advanced equipment manufacturing ranks. In order to improve the core competitiveness of China's equipment manufacturing industry, we must put great emphasis on the mechanical and electrical system design theory, equipment intelligent fault diagnosis, mechanical and electrical system integration design, manufacturing and other aspects to enhance the level of research.

Mechanical manufacturing involves many disciplines which is the frontier of research and exploration, such as modeling and simulation of electromechanical system, integration design of virtual prototype, cooperative design and simulation of multi-autonomous systems, reliability design of electromechanical system, analysis and diagnosis, intelligent expression and knowledge base management of multi domain knowledge, manufacturing process and engineering realization of mechanical and electrical products, verification and test of mechanical and electrical products, life cycle management of mechanical and electrical products, product lifecycle support environment and so on. In recent years, in the support of the National Natural Science Fund and 863 projects of national science and technology research program, our country has carried on many aspects of exploration and research in the field of mechanical manufacturing, and has made great achievements [5-6]. But generally speaking, in the construction of university innovative experimental center, our country is relatively backward in mechanical system integration design and functional simulation supporting environment, electromechanical system modeling, simulation, design, test and diagnosis of the integration of the construction. Therefore, innovation and leapfrogging must be immediately used to accelerate lab development. 


\section{EXPERIMENTAL CENTER CONSTRUCTION}

According to the needs of the development of machinery manufacturing, in accordance with the established three directions, "equipment intelligent monitoring and fault diagnosis system", "electromechanical transmission and control system of composite", "mechanical and electrical system integration design theory and method", we set up six laboratories to form an experimental center for collaborative innovation, which are "Intelligent monitoring and fault diagnosis laboratory of electromechanical system", "Mechanical and electrical system compound drive and detection laboratory", "Virtual design and optimization laboratory for mechatronic systems", "Physical field simulation and test laboratory", "Industrial robotics laboratory" and "Automotive industry collaborative innovation laboratory". Through the adjustment of the laboratory layout, the infrastructure transformation on the part of the laboratory and the acquisition of the corresponding equipment, the innovative experimental center is established, as shown in Fig.1.
(1) Intelligent monitoring and fault diagnosis laboratory of electromechanical system. This laboratory is to carry out the experiments of various mechanical behavior of mechanical equipment in the production process (especially the nonlinear mechanical behavior), which are monitoring, fault feature extraction and intelligent diagnosis methods. We use the dynamic simulation method, modern nonlinear signal detection method, the analysis method of random vibration theory and artificial intelligence to study the running behavior of mechanical equipment, nonlinear dynamics characteristics of mechanical and electrical system, random load distribution and failure mechanism of mechanism. All kinds of fault existing in the operations and the uses of the process of mechanical equipment are solved by the methods of theoretical analysis, numerical simulation and field test. What we have done is to make the equipment maintenance of complex electromechanical system develop towards high quality, high benefit, automation and intelligence.

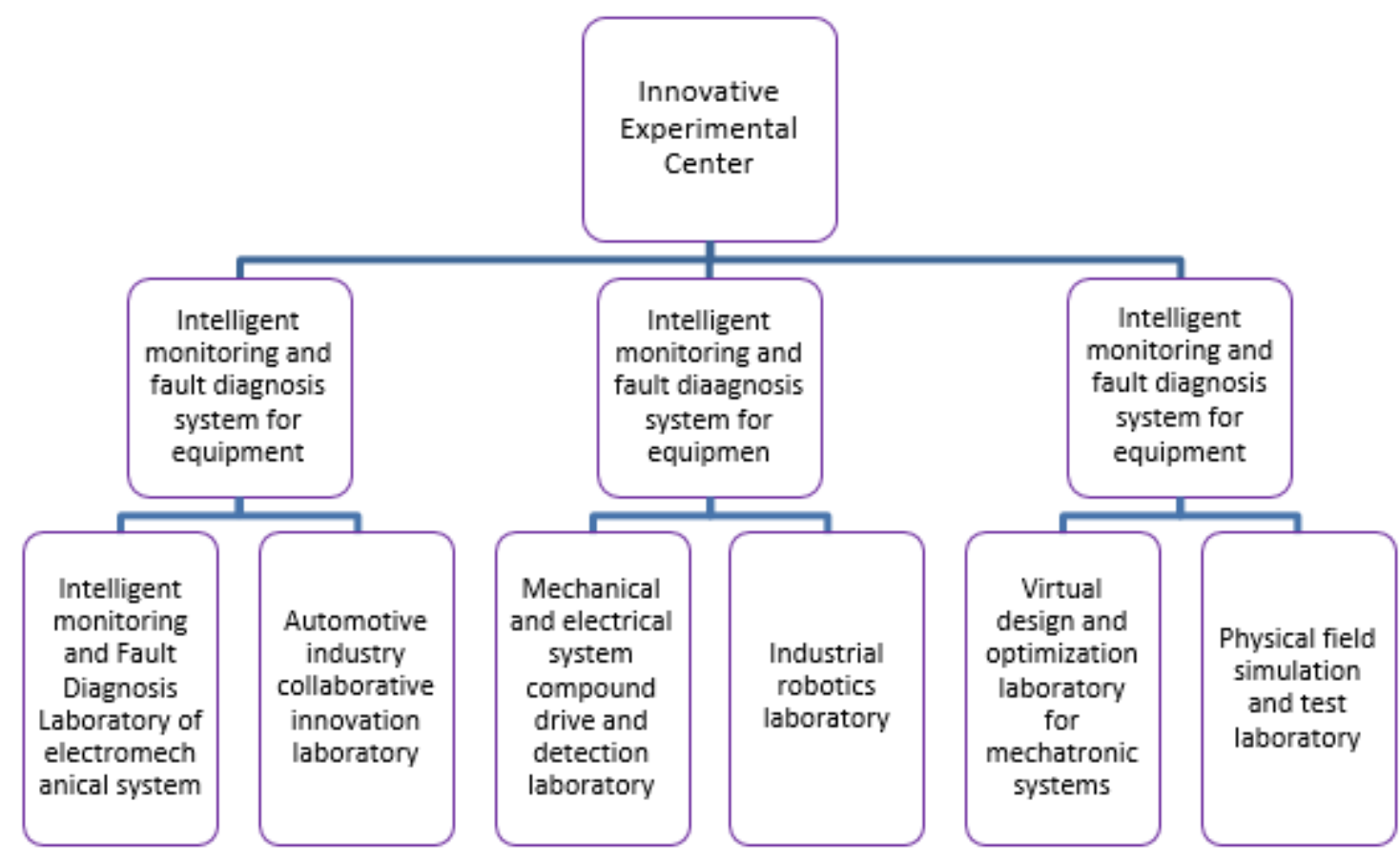

Fig. 1. Innovative Experimental Center System

(2) Mechanical and electrical system compound drive and detection laboratory. The main research direction of this laboratory is to analyze the compound drive mechanism of electromechanical system. The theory of global coupling analysis and concurrent design is applied to study the mathematical model, dynamic characteristics, operation behavior and control strategy of electromechanical system. Via simulations and experiments, we study the conditions of boundary characteristics and stability. Based on this, new mechatronic equipments are developed and manufactured, which has direct guide to the design and manufacture of mechatronic products such as large gear drives, CNC machines and hydraulic mills.
(3)Virtual design and optimization laboratory for mechatronic systems. A series of advanced technologies, such as digital virtual design technology, computer technology, CFD (Computational Fluid Dynamics) flow field simulation, finite element structure simulation, multi-body system dynamics simulation technology and optimization technology, are comprehensively applied in this laboratory to optimize the digital design and scheme of mechatronic systems.

(4) Physical field simulation and test laboratory. With the combination of modern computer technology and experimental technology, the laboratory is devoted to the research of simulation and measurement technology of 
physical field to evaluate the performance of the complex electromechanical system design scheme accurately and quickly under minimal physical experiments. A series of advanced technologies, such as computer technology, wind tunnel test technology, CFD technology, structural mechanics test technology, and finite element method, are comprehensively applied in the laboratory to provide the basis of physical field simulation for the digital design and manufacture of mechatronic systems to reach the rapid design and optimization of complex mechanical and electrical products.

(5) Industrial robotics laboratory. Industrial robots are typical representatives of the field of intelligent equipment, and the national strategy of "Made in China 2025" cannot be separated from the development of industrial robots. This laboratory combines modern design theories and methods to meet the requirements of complex and multi degree of freedom robot, the transmission accuracy and trajectory planning and design technology by considering various design factors, such as manufacturing oriented design methods, ergonomics and detection techniques. The laboratory has applied a series of advanced technologies, such as virtual design, computer technology, optimization technology, reliability theory, finite element method, sensor and detection technology and artificial intelligence to improve the digital design and structural optimization, performance improvement and reliability of the robot system.

(6) Automotive industry collaborative innovation laboratory. By introducing the equipment of the automobile enterprises around the school, and integrating school enterprise resources, an integrated and open innovation research and development system oriented to "Basic Research - Application Research - Results Industrialization" is established. This can not only solve the shortage of experimental funds and backward experimental equipment in university, but also solve the specific problems existing in the enterprise.

\section{MAIN TECHNICAL DIRECTION}

After several years of construction, the innovative experimental center has formed the following main technical directions:

(1) Intelligent monitoring and diagnosis technology of electromechanical system. In order to monitor the operation status of complex electromechanical system in time to reduce the number of stops and avoid the expansion of accidents, it is necessary to continuously monitor and control the operation parameters of the equipment. In the process of monitoring and diagnosis of complex electromechanical systems, a large amount of information can be used. The information obtained by multi-sensors system should be analyzed and processed in an intelligent manner to obtain more accurate, more comprehensive and effective information. Therefore, it is quite important to study the intelligent monitoring technology of complex electromechanical system. As has shown in Fig.2, it is a self-developed high-precision multi-channel signal testing analyzer.

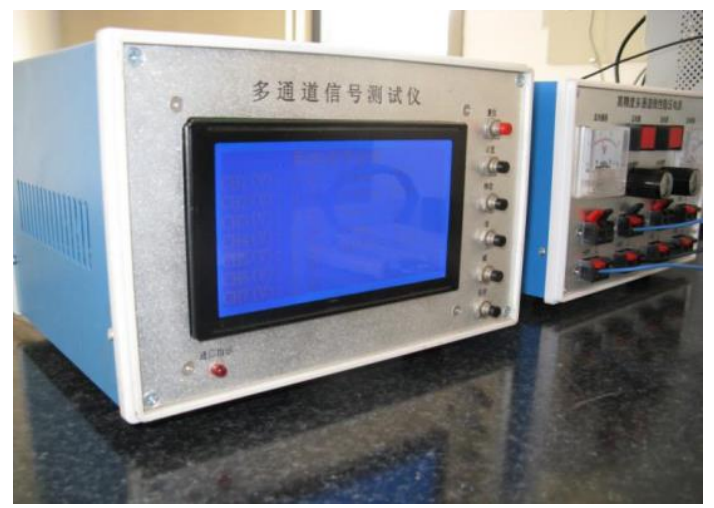

Fig. 2. High-precision multi-channel signal testing analyzer

(2) Dynamic characteristic analysis and integrated test technology of electromechanical system. The test usually adopt the parameter curve in transfer movement and power in the process (velocity curve, torque curve, transmission ratio curve, power curve and efficiency curve, etc.) of common mechanical transmission device (such as a belt drive, chain drive, gear drive, worm gear, screw drive, etc.). The system integrates frequency conversion speed regulation technology, magnetic particle brake technology, detection technology and computer testing technology and can accurately detect the transmission parameters of the transmission system. As has shown in Fig.3, it is a self-developed electromechanical system composite transmission test platform.

(3) Ultrasonic fiber grating sensing technology. Through the mechanical damage test of fiber grating sensing under multi class acoustic interaction, the detection model is modeled, simulated and analyzed, and the error precision and error compensation algorithm of different damage models are obtained. Then, we carry out multiple test corrections and adjust parameters to improve the detection of damage model. According to the identified damage model and experimental results, the correlation rules between the strain information and the damage degree of the mechanical structure are explored, and the detection and location of mechanical damage based on grating sensing are realized. As has shown in Fig.4, it is an ultrasonic fiber grating sensing device developed by ourselves.

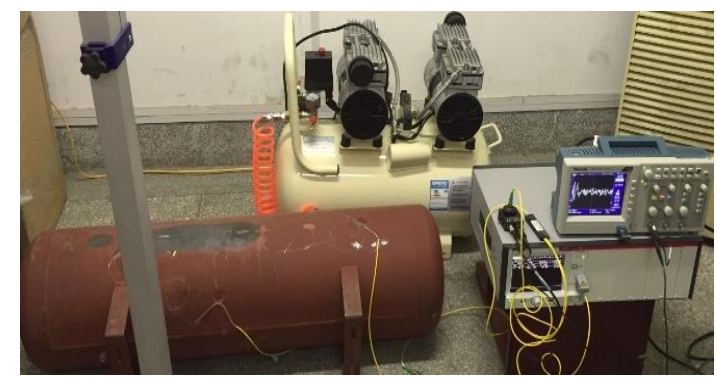

Fig. 3. Electromechanical system composite transmission test platform 


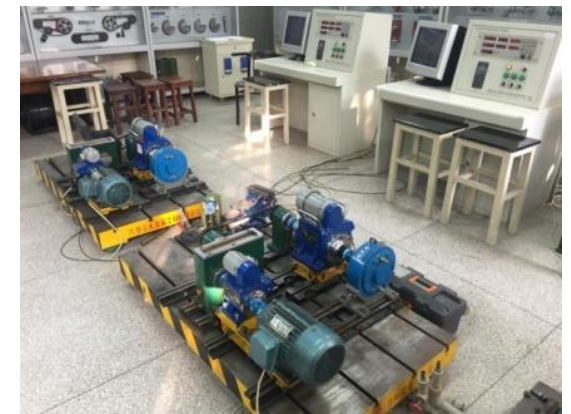

Fig. 4. Multi-degree mechanical arm

(4) Advanced transmission technology of robot system. This direction is mainly aimed at the transmission technology of robot system. In the field of general drive, the design and development of heavy duty gear drive system are carried out with the optimum carrying capacity as the design objective. The transmission accuracy calculation theory is studied in the field of high precision transmission with the drive accuracy as the goal, and we optimize the design according to the theory of design. As has shown in Fig.5, it is a self-developed multidegree mechanical arm.

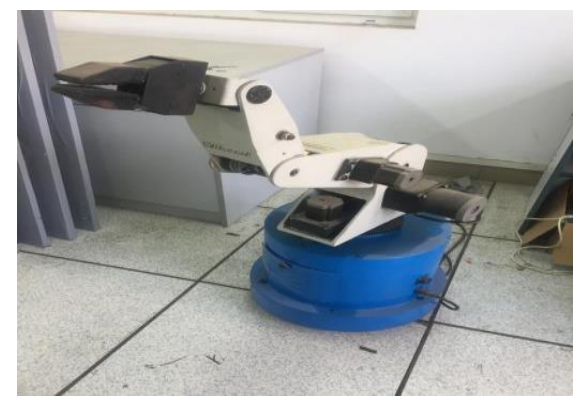

Fig. 5. Multi-degree mechanical arm

\section{CONCLUSION}

Around the "made in China 2025", it is necessary to make great efforts to meet the demand of high-end technical talents. As a key factor for the training of high-tech talents, it is particularly important for universities to set up experimental centers in the direction of equipment manufacturing. This paper analyzes the necessity of carrying out the construction of advanced equipment manufacturing direction laboratory under the national strategy deployment of "Made in China 2025". The framework of innovation research center and related research directions are proposed, which can be used as reference for the construction of relevant experimental centers in universities.

\section{REFERENCES}

[1] Mao, Xinxin. Study on the Curriculum Reform of Local Agricultural Universities in the Era of Network Curriculum. International Conference on Management Science and Innovative Education, 2016.

[2] Zeng, Huaqiang, Equipmentamp, and L. Administration. Innovation of laboratory construction and management in university-college two-level management system. Experimental Technology \& Management , 2014.

[3] Wang, Gui Rong and G. S. Yang. Study on the Reform of Laboratory Management-system in Universities Based on the Innovative Concept of Education. Technology \& Innovation Management, 2008.

[4] Jiang Sun, Qi Xiao, Manufacturing and innovation ability education of university students majored in mechanical engineering, Applied Mechanics and Materials, vol. 229-231, pp. 2779-2783, 2012.

[5] B.Williams Christopher, Gero John, Lee Yoon, Exploring the effect of design education on the design cognition of Mechanical Engineering students, Proceedings of the ASME Design Engineering Technical Conference, vol. 7, pp. 607-614, 2011.

[6] Yin Hongbiao, Lee John Chi-Kin, Wang Wenlan. Dilemmas of Leading National Curriculum Reform in a Global Era: A Chinese Perspective. Educational Management Administration \& Leadership. Vol. 42, no.2, pp.:293-311, 2013. 